\title{
Editorial
}

SSN: 2710 -0901 | ISSN-L: $2710-0901$ https://doi.org/10.33996/rebi.v2i2.1

Ing. José Alfredo Arroyo Santa Cruz

\section{Riesgos industriales y la ingeniería de riesgos}

Los lectores de la Revista REBI, para su Comité Editorial es un placer hacerle llegar este nuestro cuarto número y volumen 2, en marco de una pandemia que nos ha hecho visualizar al mundo de una manera diferente. El objeto de la revista es ser un medio de difusión de los resultados originales e inéditos de las investigaciones realizadas por profesores, profesionales y estudiantes en las áreas de la ingeniería, tecnología y afines y que proporcionan una eminente contribución al conocimiento científico y tecnológico. Esta difusión cuenta el avance y estado del conocimiento y busca su divulgación y adecuado resguardo. Nuestros lectores y público al que destinamos la revista es principalmente la comunidad científica y académica en Bolivia, América Latina y el mundo.

Los riesgos industriales traen diversos efectos en los seres vivos, proceso y productos, los que nos ha hecho visualizar la ingeniería de manera diferente. En este marco, es emblemático la construcción del famoso Golden Gate Bridge (puente colgante la ciudad de San Francisco, USA), construido durante el período de 1933 a 1937. Es emblemático ya que por primera vez se da prioridad a la seguridad de los operarios, comenzando a utilizar lentes y cascos especiales, debido a los vientos que eran sujetos durante su trabajo. Además, para limitar los riesgos de pérdidas de vidas humanas durante su construcción se instaló una red de seguridad. La misma salvó la vida de 19 hombres que, durante su construcción cayeron al vacío. Hasta febrero de 1937, cuando un andamio cae con diez (10) personas y, cuyo peso, la malla no fue capaz de soportar ocasionando un accidente fatal.

Un riesgo representa un daño potencial, el cual debe ser limitado para minimizar sus posibles efectos. Actualmente, la Ingeniería de Riesgos es una rama especializada que considera el análisis, diseño y desarrollo de programas de control de riesgos de todo tipo, no sólo los debidos a los procesos industriales, siendo una carrera en auge a nivel global. Para esta carrera existen diferentes ramas que van desde el análisis para la prevención, hasta especializados como riesgos y seguros o riesgos, seguridad y ambiente. En el marco de la pandemia del COVID-19, destaca la función de los ingenieros de estas especialidades que deben garantizar la productividad de los procesos y la salud de los trabajadores y consumidores finales. A ellos y al personal médico, enfermeras y trabajadores que, en general, todos los días salen de sus casas a garantizar la salud pública, dedicamos nuestro presente número.

En este número usted encontrará seis (6) artículos relacionados riesgos industriales, ambientales y medidas de análisis. Los tres (3) primeros tratan sobre el análisis de riesgos en la industria naval, de la fabricación de la guaya fina y en la industria petrolera. Adicionalmente, el artículo 4 trata un tema interesante como es la gestión ambiental en la industria automotriz. Finalmente, los artículos 5 y 6 versan sobre el mantenimiento de la industria 
petrolera y la reducción de viscosidad de un inductor térmico. Como podemos ver es un número con temas y aportes con una diversidad propia de ser analizada por cada uno de nuestros lectores. 